\title{
FosB transcription factor regulates COX-2 expression in colorectal cancer cells without affecting PGE2 expression
}

\author{
DIANA LIZETH CERVANTES-MADRID ${ }^{1,2}$, SABAH NAGI $^{1}$ and ANNIKA ASTING GUSTAFSSON ${ }^{1}$ \\ ${ }^{1}$ Department of Surgery, Institute of Clinical Sciences, Sahlgrenska Academy, University of Gothenburg, \\ 41345 Gothenburg, Sweden; ${ }^{2}$ Department of Basic Research, Institute of Biomedical Sciences, \\ National Autonomous University of Mexico, Mexico City 14080, Mexico
}

Received February 9, 2016; Accepted April 15, 2016

DOI: $10.3892 / \mathrm{ol} .2017 .5571$

\begin{abstract}
The expression levels of cyclooxygenase (COX)-2 and the prostaglandin E2 (PGE2) content have been associated with poor prognosis in patients with colorectal cancer (CRC). There is a strong correlation between COX-2 expression and PGE2 production in tissues from CRC patients, suggesting an important role for COX-2 on the regulation of PGE2 production. Previous studies by the present authors, where CRC patients were divided into high- or low-COX-2 expressing tumors, displayed important differences in the expression levels of several transcription factors involved in carcinogenesis. Among them, FBJ murine osteosarcoma viral oncogene homolog B (FosB), which is a member of the activator protein-1 complex, was the highest upregulated transcription factor in patients with high expression levels of COX-2. The present study aimed to investigate the role of FosB on the COX-2/PGE2 axis in CRC cells with high COX-2 expression levels. Interference RNA technology was used to knockdown FosB expression in HCA-7 cells, and $72 \mathrm{~h}$ later the messenger (m)RNA expression levels of COX-1 and COX-2, as well as the PGE2 content, were measured. The results indicated that FosB knockdown decreased the expression levels of COX-2 but did not affect the PGE2 content or the mRNA expression levels of COX-1. The present findings suggest an important role for FosB on the regulation of COX-2 expression, but no effect on the regulation of the PGE2 levels. In addition, the present results imply independent regulatory mechanisms for COX-2 expression and PGE2 content.
\end{abstract}

Correspondence to: Dr Annika Asting Gustafsson, Department of Surgery, Institute of Clinical Sciences, Sahlgrenska Academy, University of Gothenburg, Blå Stråket 5B, 41345 Gothenburg, Sweden

E-mail: annika.gustafsson@surgery.gu.se

Key words: inflammation, cancer, FosB transcription factor, COX-2, prostaglandin E2

\section{Introduction}

Colorectal cancer (CRC) is the third cause of cancer-associated mortalities in the world in men, and the second in women. In 2012, 1.36 million cases were newly diagnosed, and 694,000 patients succumbed to CRC (1). Understanding the processes that govern this disease is key to develop novel treatment strategies. In this regard, inflammation has been widely associated with cancer since 1863 (2). Patients diagnosed with inflammatory bowel disease present an increased risk to develop CRC, and the risk is higher for patients with longer disease duration and extensive disease (3). The link between inflammation and cancer has prompted an exhaustive area of research where anti-inflammatory drugs have been tested for chemoprevention and adjuvant therapy. Indomethacin, a nonsteroidal anti-inflammatory drug (NSAID), improved survival in patients with solid tumors from different origins (4). In addition, other NSAIDs, including sulindac, aspirin and piroxicam, have exhibited chemopreventive effects (5-8). Studies in the early 70 s demonstrated that aspirin and indomethacin exert their therapeutic actions partly through the inhibition of prostaglandin (PG) synthesis (9). These drugs inhibit the activity of cyclooxygenase (COX) enzymes, which transform arachidonic acid into PGH2, which is then converted into different PGs, including PGE2, PGF2 $\alpha$, PGI2, PGD2 and thromboxane A2 (9). There are two functional isoforms of COX: COX-1, whose expression is constitutive; and COX-2, which exhibits an inducible expression and whose products have been mainly associated with pathological processes (10). COX-1 expression has been reported to remain stable in cancer tissues, while COX-2 expression has been associated with advanced Dukes stage, poor long-term outcome and lymph node metastasis in CRC patients (11-13).

In previous studies by the present authors, increased COX-2 staining was able to predict tumor tissue content of PGE2 in CRC patients, while COX-1 staining had an inverse correlation with PGE2 content $(14,15)$. Furthermore, PGE2 levels were observed to be increased in premalignant adenomatous polyps and colon cancer tissues, compared with normal controls $(16,17)$. The enzyme responsible for the synthesis of PGE2 is microsomal human prostaglandin E synthase (mPGES), which is overexpressed in 
colorectal adenomas and carcinomas (18). Taken together, the COX-2/mPGES/PGE2 axis appears to be important in colorectal carcinogenesis.

Previous studies by the present authors revealed that tumor tissues from CRC patients with high COX-2 expression levels displayed upregulation of several transcription factors, among which, the most overexpressed one was FBJ murine osteosarcoma viral oncogene homolog B (FosB) (19). This transcription factor is implicated in the activator protein-1 (AP-1)/COX-2/PGE2 axis, and may play a relevant role in patients with high expression levels of COX-2. The AP-1 complex consist of homo or heterodimers of members of the Jun and Fos families, and affects proliferation, transformation, differentiation, stress response and apoptosis, depending on the composition of the complex, type of cell and microenvironment (20-22). In addition, FosB overexpression has been reported to induce malignant cell transformation in vitro and in vivo (23).

In the present study, the role of FosB on the regulation of COX-2 expression and PGE2 content was investigated in a CRC cell line that overexpressed COX-2. Small interfering (si)RNA was used to knockdown FosB expression in HCA-7 cells, and the effects on the COX/PGE2 axis were evaluated. The present results indicate that knocking down FosB induces an important decrease in COX-2 expression, with no changes on PGE2 content or COX-1 expression, suggesting that COX-2 expression and PGE2 content may be regulated by an independent mechanism.

\section{Materials and methods}

Reagents, cell lines and culture conditions. The human colon adenocarcinoma cell line HCA-7 (catalog no. 02091238; Sigma-Aldrich, St. Lois, MO, USA), which has exhibits high expression levels of COX-2, was routinely sub-cultured in Dulbecco's modified Eagle's medium (catalog no. D6546; Sigma-Aldrich) supplemented with $10 \%$ fetal bovine serum (catalog no. F2442; Sigma-Aldrich) and $1.0 \%$ of a $200-\mathrm{mM}$ L-glutamine solution (catalog no. 091680149; MP Biomedicals, LLC, Santa Ana, CA, USA) without antibiotics. Cells were maintained in a humidified incubator at $37^{\circ} \mathrm{C}$ and $5 \%$ $\mathrm{CO}_{2}$. Early passages (4-17) were used for the experiments.

siRNA knockdown. To evaluate the effect of FosB transcription factor on the COX/PGE2 axis, FosB siRNA transfection was performed. A total of $8 \times 10^{4} \mathrm{HCA}-7$ cells/well were seeded in a 6-well plate and allowed to attach overnight to achieve $30 \%$ of confluence at the time of transfection. FosB siRNA (catalog no. 4392420 ID s230577; Ambion; Thermo Fisher Scientific, Inc., Waltham, MA, USA), glyceraldehyde 3-phosphate dehydrogenase (GAPDH) positive control siRNA (catalog no. 4390849; Ambion; Thermo Fisher Scientific, Inc.) or scramble negative control siRNA (Silencer ${ }^{\circledR}$ Select Negative Control No. 1 siRNA; catalog no. 4390843; Ambion; Thermo Fisher Scientific, Inc.) were transfected into HCA-7 cells using Lipofectamine ${ }^{\circledR}$ RNAiMAX Transfection Reagent (catalog no. 13778030; Invitrogen; Thermo Fisher Scientific, Inc.). For the transfection, $5 \mu$ l Lipofectamine ${ }^{\circledR}$ RNAiMAX Transfection Reagent was added to $245 \mu \mathrm{l}$ Opti-MEM I Reduced Serum Medium (catalog no. 31985070; Thermo Fisher Scientific, Inc.), and then mixed with $10 \mathrm{nM}$ siRNA (FosB, positive control or negative control siRNA) diluted in $250 \mu \mathrm{l}$ Opti-MEM I Reduced Serum Medium. The mix was incubated for $20 \mathrm{~min}$ at room temperature prior to be added to the cells. Opti-MEM I Reduced Serum Medium was used to obtain a final volume of $2 \mathrm{ml} /$ well. At $72 \mathrm{~h}$ post-transfection, the cells and medium were collected for RNA extraction and enzyme-linked immunosorbent assay (ELISA). siRNA transfection was performed in duplicate in three independent experiments.

RNA extraction and complementary (c)DNA synthesis. Total RNA was isolated using the RNeasy Plus Micro kit (catalog no. 74034; Qiagen GmbH, Hilden, Germany), according to the manufacturer's protocol. RNA purity and concentration were measured using the RNA 6000 Nano kit (catalog no. 5067-1511) on a 2100 Bioanalyzer (both Agilent Technologies, Inc., Santa Clara, CA, USA). The sample's RNA integrity number ranged from 7 to 10 . RNA reverse transcription (RT) to cDNA was performed from $1 \mu \mathrm{g}$ total RNA using the Advantage RT-for-PCR kit (Clontech Laboratories, Inc., Mountainview, CA, USA), following the manufacturer's protocol PT1107-1 version PR023473. Oligo(dT) 18 primer was used for the synthesis of cDNA from mRNA (catalog no. 639506; Clontech Laboratories, Inc.). Negative and positive controls were performed alongside the samples during the $\mathrm{RT}$ reaction. The cycling conditions were 30 cycles of $94^{\circ} \mathrm{C}$ for $45 \mathrm{sec}, 60^{\circ} \mathrm{C}$ for $45 \mathrm{sec}$ and $72^{\circ} \mathrm{C}$ for $2 \mathrm{~min}$, with a final extension at $72^{\circ} \mathrm{C}$ for $7 \mathrm{~min}$, using an Eppendorf MasterCycler Gradient (Eppendorf-Netheler-Hinz GmbH, Hamburg, Germany).

Quantitative polymerase chain reaction ( $q P C R)$. A total of $2 \mu \mathrm{lcDNA}$ was used to analyze the expression of FosB, COX-2, COX-1, GAPDH and 18S. The following QuantiTect Primer Assays (Qiagen $\mathrm{GmbH}$ ) were used: Hs_FOSB_1_SG (FosB), Hs_PTGS2_1_SG (COX-2), Hs_PTGS1_1_SG (COX-1), Hs_GAPDH_1_SG (GAPDH) and Hs_RRN18S_1_SG (18S). qPCR was performed in a LightCycler 1.5 instrument (Roche Applied Science, Penzberg, Germany) using LightCycler FastStart DNA MasterPLUS SYBR Green I kit (catalog no. 03515885001; Roche Applied Science), according to the manufacturer's protocol. The cycling conditions were as follows: Activation at $95^{\circ} \mathrm{C}$ for $10 \mathrm{~min}$, denaturation at $95^{\circ} \mathrm{C}$ for $10 \mathrm{sec}$ and annealing at $64^{\circ} \mathrm{C}$ for $4 \mathrm{sec}$ in 40 cycles for FosB, GAPDH and $18 \mathrm{~S}$, or 45 cycles for COX-1 and COX-2. Gene expression was analyzed using the relative standard curve method. COX-1 and COX-2 mRNA expression levels were normalized to those of $18 \mathrm{~S}$ and GAPDH, whereas FosB mRNA expression levels were normalized using only $18 \mathrm{~S}$ as a control gene, since GAPDH was used as a positive control for FosB siRNA experiments. Data are presented as the mean \pm standard error of the mean (SEM) of the GAPDH and $18 \mathrm{~S}$ normalized values. Fold-changes were calculated using the negative control as a calibrator.

ELISA. To analyze the effect of FosB knockdown on the production of PGE2, ELISA for PGE2 was performed at $72 \mathrm{~h}$ post-FosB siRNA transfection. Briefly, $500 \mu \mathrm{l}$ medium 
was collected from the FosB siRNA-transfected and control samples, and processed according to the Biotrak EIA system protocol for PGE2 (catalog no. RPN222; Amersham; GE Healthcare Life Sciences, Chalfont, UK). The absorbance was measured at $630 \mathrm{~nm}$ in an Epoch Microplate Spectrophotometer (Biotek Instruments, Inc., Winooski, VT, USA). Determination of the sample concentrations (pg/well) was conducted according to the manufacturer's protocol using a standard curve. Each siRNA-transfected sample was analyzed in triplicate. Data are presented as the mean \pm SEM of three independent experiments performed in duplicate, compared with the negative control (scramble siRNA).

Cell imaging. At $72 \mathrm{~h}$ post-transfection with FosB siRNA, imaging of cells was performed using an AE200 microscope with a 10X objective (Motic Instruments, Richmond, BC, Canada).

Statistical Analysis. Data are presented as the mean \pm SEM from three independent experiments performed in duplicate or triplicate. Statistical differences between the control group and treated cells were evaluated using an independent $t$ test. Statistical analyses were performed using SPSS software version 22.0.0.0 (IBM SPSS, Armonk, NY, USA). P<0.05 was considered to indicate a statistically significant difference.

\section{Results}

FosB knockdown by siRNA reduces $C O X-2$ mRNA expression but does not affect PGE2 extracellular content. To study the effects of FosB upregulation in cells with high COX-2 expression levels, FosB expression was knocked down on HCA-7 cells using siRNA. To standardize the siRNA treatment, HCA-7 cells were treated with the minimum siRNA concentration recommended by the manufacturer $(10 \mathrm{nM})$ and with different concentrations of Lipofectamine ${ }^{\circledR}$ RNAiMAX Transfection Reagent $(0.5,3,4$ and $5 \mu 1)$. The treatment was stopped at different time points, and the RNA content was analyzed by RT-qPCR. The data was normalized using $18 \mathrm{~S}$ as a control gene. Treatment for $72 \mathrm{~h}$ achieved the most significant reduction in FosB mRNA expression in FosB siRNA-transfected cells ( 24 h, $\mathrm{P}=0.397 ; 48$ h, $\mathrm{P}=0.106 ; 72 \mathrm{~h}, \mathrm{P}=0.00062$; and $96 \mathrm{~h}$, $\mathrm{P}=0.00533)$. Therefore, this time point was selected for further experiments. There was no significant difference between FosB mRNA expression in untreated cells and in negative control cells ( $\mathrm{P}=0.240$; data not shown). The transfection of HCA-7 cells with FosB siRNA induced a significant decrease in FosB mRNA expression levels at $72 \mathrm{~h}(75 \pm 9 \%$ reduction, compared with the negative control $(\mathrm{P}=0.002$; Fig. 1).

To evaluate the effect of FosB knockdown on COX-2 expression, the levels of COX-2 mRNA on cells transfected with FosB siRNA were evaluated at $72 \mathrm{~h}$ using qPCR. COX-2 expression was normalized using GAPDH and $18 \mathrm{~S}$ as control genes. The results revealed a significant decrease in COX-2 mRNA levels in FosB-knocked down cells (fold-change, $0.11 \pm 0.02)$, compared with negative control cells $(\mathrm{P}=0.018$; Fig. 2). To further study the effect of FosB knockdown on the COX-2/PGE2 axis, the PGE2 content in the medium of

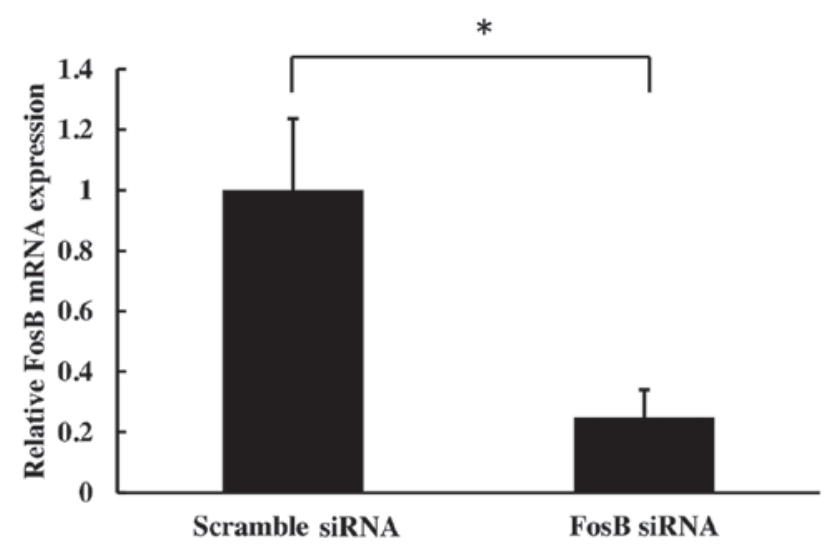

Figure 1. Treatment with FosB siRNA effectively decreased the mRNA expression of the FosB gene. HCA-7 cells were transfected with FosB siRNA and subjected to RNA isolation $72 \mathrm{~h}$ later. FosB mRNA expression was quantified by reverse transcription-quantitative polymerase chain reaction. Data are presented as the mean \pm standard error of the mean of three independent experiments performed in duplicate and analyzed as fold-changes in gene expression compared with the negative control (scramble siRNA). ${ }^{*} \mathrm{P}=0.002$ vs. control. si, small interfering; mRNA, messenger RNA; FosB, FBJ murine osteosarcoma viral oncogene homolog B.

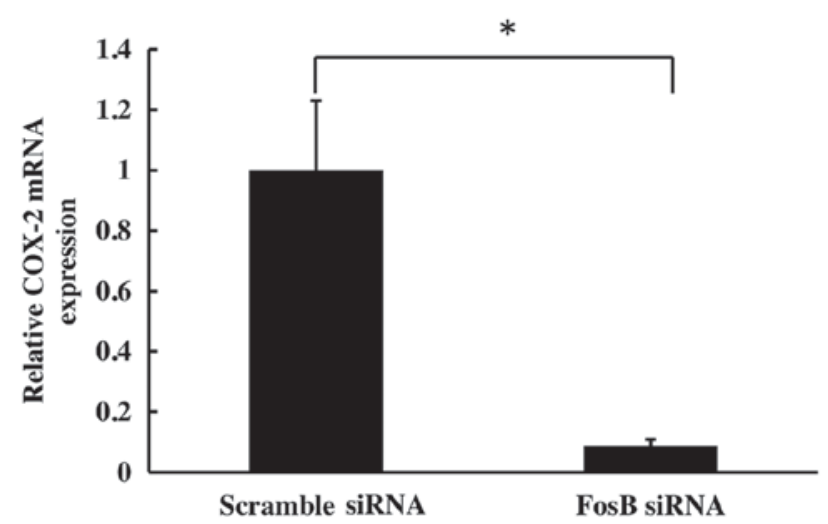

Figure 2. FosB siRNA-transfected cells significantly decreased their COX-2 mRNA expression levels. COX-2 gene expression was measured in HCA-7 cells transfected with FosB siRNA following $72 \mathrm{~h}$ by reverse transcription-quantitative polymerase chain reaction. Data are presented as the mean \pm standard error of the mean of three independent experiments performed in duplicate and analyzed as fold-changes in gene expression compared with the negative control (scramble siRNA). ${ }^{*} \mathrm{P}=0.018$ vs. control. si, small interfering; mRNA, messenger RNA; FosB, FBJ murine osteosarcoma viral oncogene homolog $\mathrm{B}$; $\mathrm{COX}$, cyclooxygenase.

FosB-knocked down cells was measured using ELISA. The extracellular levels of PGE2 remained unchanged in FosB siRNA-transfected cells, compared with those in negative control cells ( $\mathrm{P}=0.980$; Fig. 3$)$.

COX-1 mRNA expression is not affected by FosB knockdown. Following $72 \mathrm{~h}$ of FosB siRNA transfection, there was no significant change in COX-1 mRNA expression between FosB siRNA-tranfected cells and negative control cells $(\mathrm{P}>0.450$; Fig. 4).

Morphological changes following FosB knockdown. During the course of the FosB siRNA transfection experiments, differences in the morphology of FosB-knocked down cells vs. control cells 


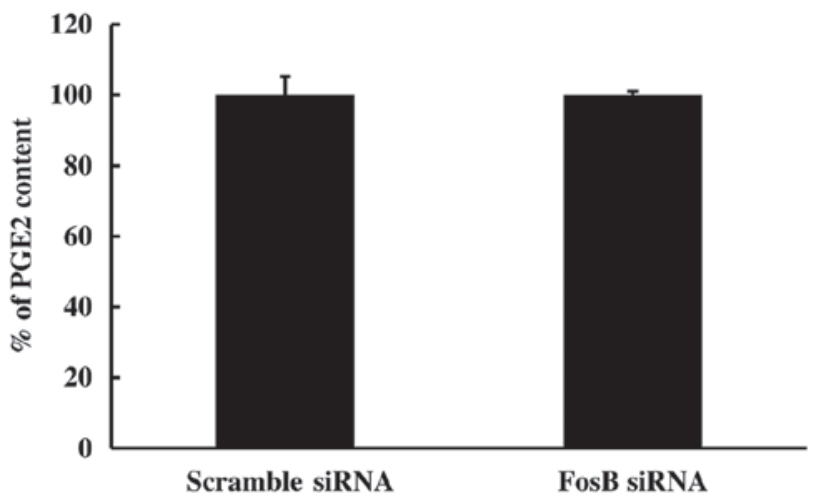

Figure 3. PGE2 content was not affected by FosB knockdown. PGE2 content was measured by enzyme-linked immunosorbent assay in HCA-7 cells transfected with FosB siRNA at $72 \mathrm{~h}$ post-transfection. Data are presented as the mean \pm standard error of the mean of the concentration of PGE2/well from three independent experiments performed in triplicate. There was no significant difference between the FosB siRNA and the scramble siRNA groups ( $\mathrm{P}=0.980$ vs. control). $\mathrm{PGE} 2$, prostaglandin $\mathrm{E} 2$; si, small interfering; mRNA, messenger RNA; FosB, FBJ murine osteosarcoma viral oncogene homolog B.

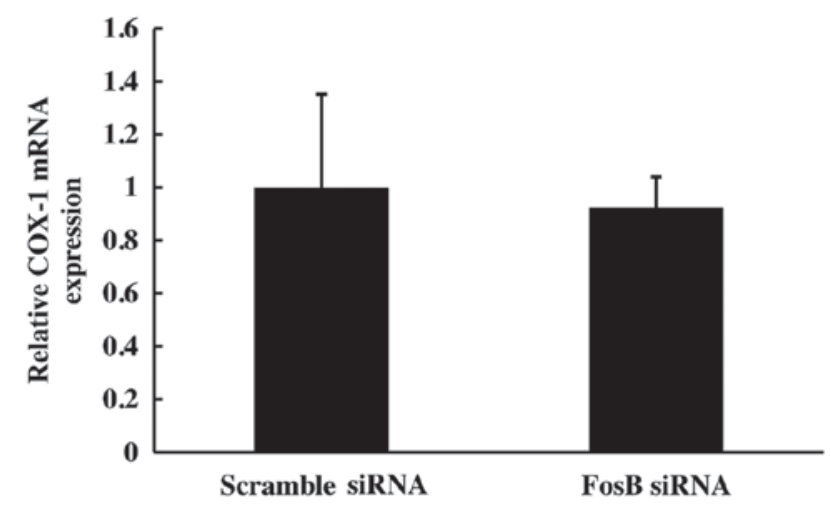

Figure 4. FosB siRNA transfection did not affect the mRNA levels of COX-1. COX-1 gene expression was measured in HCA-7 cells transfected with FosB siRNA at $72 \mathrm{~h}$ post-transfection by reverse transcription-quantitative polymerase chain reaction. Data are presented as the mean \pm standard error of the mean of three independent experiments performed in duplicate and analyzed as fold-changes in gene expression compared with the scramble siRNA group ( $\mathrm{P}=0.450$ vs. control). si, small interfering; mRNA, messenger RNA; FosB, FBJ murine osteosarcoma viral oncogene homolog B; COX, cyclooxygenase.

were noticed. Fig. 5A represents the FosB siRNA-transfected cells, while Fig. 5B represents the negative control cells.

\section{Discussion}

Inflammation has an important role on CRC carcinogenesis. Inflammatory molecules, including COX-2 and PGE2, are increased in tumor tissues of CRC patients, and theirhigh expression has been associated with poor outcomes $(11,12,14,16,17)$. Drugs capable of inhibiting COX enzymes such as NSAIDs have demonstrated chemopreventive and antitumoral potential in animal models and humans (4-8). However, the therapeutic effects of NSAIDs varied among different CRC patients. These discrepancies may be due to the variations in the expression levels of COX-2 and gene mutational status across patients (24-26), since those with high COX-2 expression
A

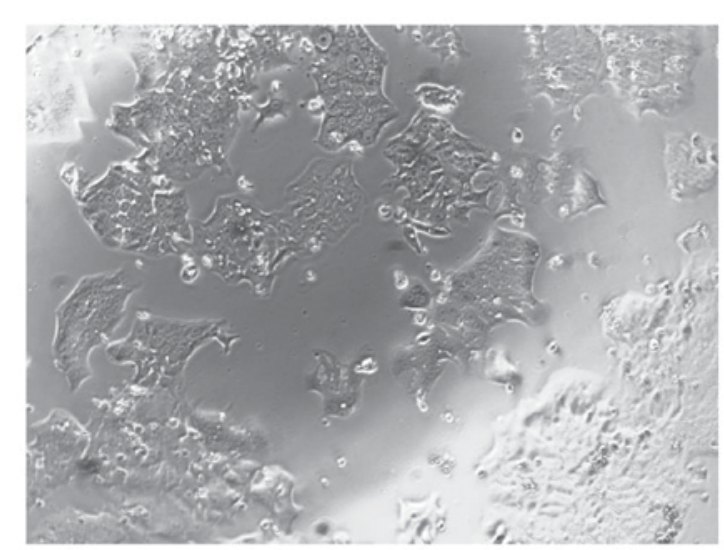

B

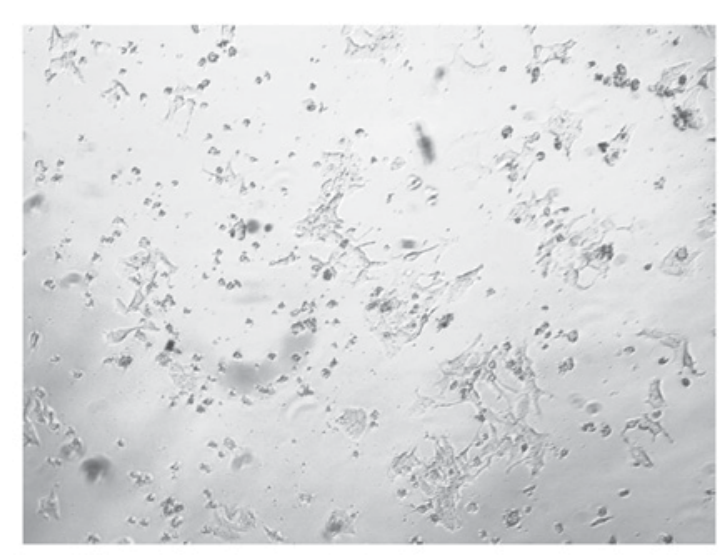

Figure 5. (A) HCA-7 cells transfected with FosB siRNA presented morphological changes at $72 \mathrm{~h}$ post-transfection, compared with (B) cells transfected with scramble siRNA (negative control). Magnification, $\mathrm{x} 10$. si, small interfering; FosB, FBJ murine osteosarcoma viral oncogene homolog B.

levels and mutations in phosphatidylinositol-4,5-bisphosphate 3-kinase catalytic subunit alpha exhibited improved survival with NSAID treatment (24).

Despite the important role of COX-2 and PGE2 in $\mathrm{CRC}$, the mechanisms that regulate the expression of these two molecules are still not well understood. Previous studies by the present authors correlated the expression of COX-2, but not that of COX-1, to the PGE2 content in tissues from CRC patients (14), thus suggesting a common regulatory mechanism for COX-2 expression and PGE2 production. Since PGE2 is a downstream product of $\mathrm{COX}-2$, it is possible to assume that the expression of COX-2 may affect the levels of PGE2. A previous study by the present authors proposed FosB as an important transcription factor in CRC patients with high COX-2 tumor tissue expression, since FosB was overexpressed in these patients, comparing with patients who exhibited low COX-2 expression (19). FosB is a member of the AP-1 complex, which has been linked to malignant transformation in several types of cancer, and its components, including FosB, have important roles on cell proliferation (among other functions), which suggests their involvement in cancer development (27-30). In the present study, the role of FosB on the COX-2/PGE2 axis was investigated. The results revealed that FosB knockdown induced an important decrease on COX-2 expression, while the PGE2 content was not changed. These results suggest that the levels of PGE2 may be regulated by mechanisms independent of COX-2 expression, regardless of the fact that COX-2 
expression is able to predict the content of PGE2 in CRC tissues. Since the extracellular levels of PGE2 did not change in cells with FosB knockdown, despite a marked decrease on COX-2 mRNA expression in these cells, the present findings imply that there are other important players in the production of PGE2. As PGE2 could also be synthesized by COX-1, the expression levels of this enzyme were also measured in the present study, and it was observed that the knockdown of FosB did not affect COX-1 expression, which is in agreement with a constitutive expression of COX-1 in the tested cells. Since FosB knockdown is able to decrease COX-2 expression, but neither COX-1 expression nor PGE2 content, it is possible to suggest that FosB transcription factor is important in the regulation of COX-2 expression, but is not involved in the regulation of enzymes catalyzing the direct synthesis of PGE2 or in the regulation of COX-1 expression. In the present study, important changes in cell morphology were observed subsequent to FosB knockdown, which may be explained by the role of FosB in processes such as stress response, proliferation and apoptosis (20).

Previous reports support the present finding that PGE2 content is not changed upon decreasing COX-2 expression (31-35). A number of authors have demonstrated that in the $V h l^{\mathrm{SIE}} / A p c^{\mathrm{min} /+}$ intestinal tumor model, the production of PGE2 is not dependent on the levels of COX-2, since despite the blockage of COX-2 activity by nimesulide, the PGE2 content remained elevated, suggesting that the high PGE2 levels observed were due to an increase in mPGES1 expression $(31,32)$. The high expression of COX-2 and mPGES1 in their studies was explained by the direct activation of the promoter region of these two genes by hypoxia-inducible factor $2 \alpha(31)$, which associates hypoxia with the COX-2/mPGES1/PGE2 axis. In other report, PGs were able to induce $\mathrm{mPGES} 1$ expression through the activation of early growth response 1 , implying a positive regulatory feedback between these components (33). In addition, mPGES1 has been observed to be increased in CRC tumor tissues and to correlate with a worse prognosis (34). Almendingen et al (35) reported that treatment with rofecoxib, a COX-2 selective inhibitor, did not affect the PGE2 levels in plasma of patients with familial adenomatous polyposis. Altogether, those findings offer an explanation for the present results. Thus, it is possible that high expression of mPGES1 contributes to high PGE2 levels independently of a reduced COX-2 expression. Considering that the levels of COX-1 and PGE2 remain unchanged following FosB knockdown, it is also possible that basal COX-1 expression maintains the PGE2 levels. Further studies are required to investigate in more detail the regulation of $\mathrm{COX}-2$ expression and PGE2 content, as well as the role of FosB as a regulatory factor in COX-2 expression.

The present study aids to explain the regulatory mechanisms behind the expression of COX-2. As NSAIDs have been regarded as potential chemopreventive and/or adjuvant agents for cancer treatment, particularly in CRC patients (19), due to their inhibitory effect on COX enzymes, it is important to understand the mechanisms by which these enzymes exert their actions in the process of carcinogenesis. The development of more effective therapies using combinations of NSAIDs and other inhibitors of the PG pathways depend on a deeper knowledge in this matter.
In conclusion, the present study has demonstrated that FosB partly regulates COX-2 expression in HCA-7 cells with no apparent participation in the regulation of PGE2 production.

\section{Acknowledgements}

D. L. C-M was a PhD student in the Doctoral Program in Biomedical Sciences of the National Autonomous University of Mexico (Mexico City, Mexico), and received a scholarship from the National Council of Science and Technology (Mexico City, Mexico; grant no. 245314), the Program of Support for Postgraduate Studies and the Mobility Program of International Students of the General Direction of Postgraduate Studies of the National Autonomous University of Mexico (Mexico City, Mexico). The present study was partly supported by grants from the Swedish Cancer Society (Stockholm, Sweden; grant nos. 2014 and 4261), the Swedish Research Council (Stockholm, Sweden; grant nos. 08712, 13268 and 11611), Assar Gabrielsson Foundation (AB Volvo, Gothenburg, Sweden), the Magnus Bergvall Foundation (Stockholm, Sweden), the Sahlgrenska University Hospital Foundation (Gothenburg, Sweden), the Wilhelm and Martina Lundgren Foundation (Stockholm, Sweden) and the Tore Nilsson Foundation (Stockholm, Sweden).

\section{References}

1. International Agency for Research on Cancer: GLOBOCAN 2012: Estimated cancer incidence, mortality and prevalence worldwide in 2012. http://globocan.iarc.fr/Pages/fact_sheets_ population.aspx. Accessed January 5, 2016.

2. Coussens LM and Werb Z: Inflammation and cancer. Nature 420: 860-867, 2002

3. Lutgens MW, van Oijen MG, van der Heijden GJ, Vleggaar FP, Siersema PD and Oldenburg B: Declining risk of colorectal cancer in inflammatory bowel disease: An updated meta-analysis of population-based cohort studies. Inflamm Bowel Dis 19: 789-799, 2013.

4. Lundholm K, Gelin J, Hyltander A, Lönnroth C, Sandström R, Svaninger G, Körner U, Gülich M, Kärrefors I and Norli B: Anti-inflammatory treatment may prolong survival in undernourished patients with metastatic solid tumors. Cancer Res 54: 5602-5606, 1994.

5. Thun MJ, Namboodiri MM and Heath CW Jr: Aspirin use and reduced risk of fatal colon cancer. N Engl J Med 325: 1593-1596, 1991.

6. Narisawa T, Sato M, Tani M, Kudo T, Takahashi T and Goto A: Inhibition of development of methylnitrosourea-induced rat colon tumors by indomethacin treatment. Cancer Res 41: 1954-1957, 1981.

7. Rao CV, Tokumo K, Rigotty J, Zang E, Kelloff G and Reddy BS: Chemoprevention of colon carcinogenesis by dietary administration of piroxicam, alpha-difluoromethylornithine, 16 alphafluoro-5-androsten-17-one, and ellagic acid individually and in combination. Cancer Res 51: 4528-4534, 1991.

8. Moorghen M, Ince P, Finney KJ, Sunter JP, Appleton DR and Watson AJ: A protective effect of sulindac against chemically-induced primary colonic tumours in mice. J Pathol 156: 341-347, 1988

9. Vane JR: Inhibition of prostaglandin synthesis as a mechanism of action for aspirin-like drugs. Nat New Biol 231: 232-235, 1971.

10. Rouzer CA and Marnett LJ: Cyclooxygenases: Structural and functional insights. J Lipid Res 50 Suppl: S29-S34, 2009.

11. Sano H, Kawahito Y, Wilder RL, Hashiramoto A, Mukai S, Asai K, Kimura S, Kato H, Kondo M and Hla T: Expression of cyclooxygenase-1 and -2 in human colorectal cancer. Cancer Res 55: 3785-3789, 1995.

12. Sheehan KM, Sheahan K, O'Donoghue DP, MacSweeney F, Conroy RM, Fitzgerald DJ and Murray FE: The relationship between cyclooxygenase- 2 expression and colorectal cancer. JAMA 282: 1254-1258, 1999. 
13. Kunzmann AT, Murray LJ, Cardwell CR, McShane CM, McMenamin UC and Cantwell MM: PTGS2 (cyclooxigenase-2) expression and survival among colorectal cancer patients: A systematic review. Cancer Epidemiol Biomarkers Prev 22: 1490-1497, 2013

14. Cahlin C, Lönnroth C, Arvidsson A, Nordgren S and Lundholm K: Growth associated proteins in tumor cells and stroma related to disease progression of colon cancer accounting for tumor tissue PGE2 content. Int J Oncol 32: 909-918, 2008.

15. Wang D and DuBois RN: An inflammatory mediator, prostaglandin E2, in colorectal cancer. Cancer J 19: 502-510, 2013.

16. Rigas B, Goldman IS and Levine L: Altered eicosanoid levels in human colon cancer. J Lab Clin Med 122: 518-523, 1993.

17. Pugh S and Thomas GA: Patients with adenomatous polyps and carcinomas have increased colonic mucosal prostaglandin E2. Gut 35: 675-678, 1994.

18. Yoshimatsu K, Golijanin D, Paty PB, Soslow RA, Jakobsson PJ, DeLellis RA, Subbaramaiah K and Dannenberg AJ: Inducible microsomal prostaglandin $\mathrm{E}$ synthase is overexpressed in colorectal adenomas and cancer. Clin Cancer Res 7: 3971-3976, 2001.

19. Asting AG, Carén H, Andersson M, Lönnroth C, Lagerstedt K and Lundholm K: COX-2 gene expression in colon cancer tissue related to regulating factors and promoter methylation status. BMC Cancer 11: 238, 2011

20. Ashida R, Tominaga K, Sasaki E, Watanabe T, Fujiwara Y, Oshitani N, Higuchi K, Mitsuyama S, Iwao H and Arakawa T: AP-1 and colorectal cancer. Inflammopharmacology 13: 113-125, 2005.

21. Yang F, Nam S, Zhao R, Tian Y, Liu L, Horne DA and Jove R: A novel synthetic derivative of the natural product berbamine inhibits cell viability and induces apoptosis of human osteosarcoma cells, associated with activation of JNK/AP-1 signaling. Cancer Biol Ther 14: 1024-1031, 2013.

22. Shaulian E and Karin M: AP-1 in cell proliferation and survival. Oncogene 20: 2390-2400, 2001.

23. Kovary K, Rizzo CA, Ryseck RP, Noguchi T, Raynoschek C, Pelosin JM and Bravo R: Constitutive expression of FosB and its short form, FosB/SF, induces malignant cell transformation in rat-A1 cells. New Biol 3: 870-879, 1991.

24. Liao X, Lochhead P, Nishihara R, Morikawa T, Kuchiba A Yamauchi M, Imamura Y, Qian ZR, Baba Y, Shima K, et al: Aspirin use, tumor PIK3CA mutation, and colorectal-cancer survival. N Engl J Med 367: 1596-1606, 2012.

25. Chan AT, Ogino S and Fuchs CS: Aspirin use and survival after diagnosis of colorectal cancer. JAMA 302: 649-658, 2009.

26. Chan AT, Ogino S and Fuchs CS: Aspirin and the risk of colorectal cancer in relation to the expression of COX-2. N Engl J Med 356: 2131-2142, 2007.
27. Babu RL, Naveen Kumar M, Patil RH, Devaraju KS, Ramesh GT and Sharma SC: Effect of estrogen and tamoxifen on the expression pattern of AP-1 factors in MCF-7 cells: Role of c-Jun, c-Fos, and Fra-1 in cell cycle regulation. Mol Cell Biochem 380: 143-151, 2013.

28. Harwood FG, Kasibhatla S, Petak I, Vernes R, Green DR and Houghton JA: Regulation of FasL by NF-kappaB and AP-1 in Fas-dependent thymineless death of human colon carcinoma cells. J Biol Chem 275: 10023-10029, 2000.

29. Kim YJ, Yoon SY, Kim JT, Choi SC, Lim JS, Kim JH, Song EY, Lee HG, Choi I and Kim JW: NDRG2 suppresses cell proliferation through down-regulation of AP-1 activity in human colon carcinoma cells. Int J Cancer 124: 7-15, 2009.

30. Rivat C, Le Floch N, Sabbah M, Teyrol I, Redeuilh G, Bruyneel E, Mareel M, Matrisian LM, Crawford HC, Gespach C and Attoub S: Synergistic cooperation between the AP-1 and LEF-1 transcription factors in the activation of the matrilysin promoter by the src oncogene: Implications in cellular invasion. FASEB J 17: 1721-1723, 2003.

31. Xue X and Shah YM: Hypoxia-inducible factor- $2 \alpha$ is essential in activating the COX-2/mPGES-1/PGE2 signaling axis in colon cancer. Carcinogenesis 34: 163-169, 2013.

32. Xue X, Taylor M, Anderson E, Hao C, Qu A, Greenson JK, Zimmermann EM, Gonzalez FJ and Shah YM: Hypoxia-inducible factor- $2 \alpha$ activation promotes colorectal cancer progression by dysregulating iron homeostasis. Cancer Res 72: 2285-2293, 2012.

33. Stamatakis K, Jimenez-Martinez M, Jimenez-Segovia A, Chico-Calero I, Conde E, Galán-Martínez J, Ruiz J, Pascual A, Barrocal B, López-Pérez R, et al: Prostaglandins induce early growth response 1 transcription factor mediated microsomal prostaglandin E2 synthase up-regulation for colorectal cancer progression. Oncotarget 6: 39941-39959, 2015.

34. Seo T, Tatsuguchi A, Shinji S, Yonezawa M, Mitsui K, Tanaka S, Fujimori S, Gudis K, Fukuda Y and Sakamoto C: Microsomal prostaglandin E synthase protein levels correlate with prognosis in colorectal cancer patients. Virchows Arch 454: 667-676, 2009.

35. Almendingen K, Larsen LN, Fausa O, Bratlie J, Høstmark AT and Aabakken L: Selective COX-2 inhibition affects fatty acids, but not COX mRNA expression in patients with FAP. Fam Cancer 9: 571-580, 2010. 